\title{
Characterization of Buriti (Mauritia flexuosa L.) Oil by Absorption and Emission Spectroscopies
}

\author{
Marcos L. S. Albuquerque ${ }^{a}$, Ilde Guedes ${ }^{a}$, Petrus Alcantara Jr. ${ }^{b}$, Sanclayton G. C. Moreira ${ }^{b}$, \\ Newton M. Barbosa Neto ${ }^{*, c}$, Daniel S. Correa ${ }^{c}$ and Sergio C. Zilio ${ }^{c}$ \\ ${ }^{a}$ Departamento de Física, Universidade Federal do Ceará, Campus do Pici, CP 6030, \\ 60455-970 Fortaleza - CE, Brazil \\ ${ }^{b}$ Departamento de Física, Universidade Federal do Pará, Campus do Guamá, 66715-110 Belém - PA, Brazil \\ ${ }^{c}$ Departamento de Física e Ciência dos Materiais, Instituto de Física de São Carlos, Universidade de São Paulo,
} CP 369, 13560-970 São Carlos - SP, Brazil

\begin{abstract}
Amostras de óleo obtido do fruto do Buriti (Mauritia flexuosa L.) foram caracterizadas por espectroscopia de absorção e emissão. O espectro de absorção foi obtido no intervalo de 300 a 2000 $\mathrm{nm}$, enquanto o espectro de emissão foi analisado entre 400 e $800 \mathrm{~nm}$, onde observamos várias bandas. Para melhor entender a complexidade destes espectros, também obtivemos os espectros de absorção e emissão dos componentes majoritários do óleo de Buriti. Correlacionando estes dados, apresentamos uma discussão sobre a origem das bandas observadas.
\end{abstract}

Oil samples obtained from Buriti (Mauritia flexuosa L.) palm tree fruits were characterized by absorption and emission spectroscopies. The absorption spectrum was recorded in the range from 300 to $2000 \mathrm{~nm}$, while the emission spectrum was analyzed between 400 and $800 \mathrm{~nm}$, where several bands were observed. To better understand these complex spectra, we recorded both absorption and emission spectra of its major components. By correlating these data, we present a discussion on the possible origin of the bands observed.

Keywords: vegetable oil, Mauritia flexuosa, absorption and emission spectra

\section{Introduction}

In the last few years several Amazon vegetable oils, including Buriti, ${ }^{1}$ Copaiba, ${ }^{2,3}$ and Babaçu ${ }^{4}$ oils, have been studied. To make sure that they are suitable for commercial use, it is very important to investigate their chemical and physical properties. In particular, we are interested in Buriti oil, which was previously characterized as being composed mainly by fatty acids, tocopherols and carotenes. ${ }^{5}$ Some of its characteristics are: red-orange color due to presence of carotenes, density of $0.86 \mathrm{~g} \mathrm{~cm}^{-3}$, refractive index of 1.46 at $22{ }^{\circ} \mathrm{C}$, iodine index of $77.2 \mathrm{cg} \mathrm{I}_{2}$ per $100 \mathrm{~g}$, saponification index of $169.9 \mathrm{mg} \mathrm{KOH}$ per $\mathrm{g}$ and melting point at $12{ }^{\circ} \mathrm{C}$. Tocopherols, one of the constituents of Buriti oil, are natural anti-oxidants forming vitamin E. Among the eight different natural tocopherols presenting vitamin $\mathrm{E}$ activity, $\alpha$-tocopherol is the most important, corresponding to $90 \%$ of the total amount of tocopherols

\footnotetext{
* e-mail: newton@if.sc.usp.br
}

in animal tissues and has the largest biological activity. The fatty acids, also present in the Buriti oil, are of long chain, given that they have more than 10 carbon atoms in their structure. Besides these components, Buriti and vegetable oils in general, present some amount of chlorophyll A in their chemical composition. The chlorophyll A may be present in the peel and pulp of the fruit.

Recently, thermal properties of Buriti, Copaiba, Pequi and Babaçu oils were analyzed by the thermal lens technique. ${ }^{6}$ In addition, physical and chemical properties of Buriti oil were characterized by means of dielectric loss and differential scanning calorimetry measurements. ${ }^{1}$ The analysis of its infrared absorption spectrum and the assignment of the bands observed between 650 and 4000 $\mathrm{cm}^{-1}$ have recently been reported. ${ }^{7}$ The spectrum is very similar to that of triolein, a triglyceride of oleic acid. This result suggests that Buriti oil is a potential candidate to prevent LDL cholesterol. Its use to enhance biodisel has been investigated by da Rocha et al. ${ }^{8}$ They analyzed the 
formation of alkanes, alkylcycloalcanes and alkylbenzenes during the catalytic hydrocracking of Buriti oil. Ongoing in the characterization of Buriti oil, here we focus on its absorption and emission spectra in the range 300-2000 nm. The assignment of both absorption and emission bands of the Buriti oil was performed based on correlations with the bands present in its individual components.

\section{Experimental}

\section{Samples}

The Buriti fruit was collected from a palm tree abundant in the Amazon region. Approximately, the fruit presents the following composition: $20 \%$ of shell and pulp, $30 \%$ of white cellulose layer and $50 \%$ of seed ( $\mathrm{m} / \mathrm{m}$ of fruit). After removing the white cellulose layer and the seeds, the resulting shell and pulp were dried in an oven with air circulation at $60{ }^{\circ} \mathrm{C}$ for $24 \mathrm{~h}$. The dried solid material was then ground in a comminuting mill and sifted for $30 \mathrm{~min}$ in a sieve shaker fitted with sieves of different sizes. Absorption and fluorescence measurements were carried out by using the Buriti oil as extracted. The extracts were analyzed with respect to total carotenes in a spectrophotometer and to other components (free fatty acid and tochopherols) by gas chromatography using the same procedure described before. ${ }^{1}$ Table 1 presents the oil composition used in this work.

Table 1. Composition of the Buriti oil

\begin{tabular}{lll}
\hline Substance & Amount \\
\hline $\begin{array}{l}\text { Carotenoids (ppm) } \\
\text { Tocopherols (ppm) }\end{array}$ & 1707 \\
$\begin{array}{l}\text { Free fatty acid composition }(\%) \\
\text { Saturated fatty acid }\end{array}$ & 800 \\
& Miristic & 0.1 \\
& Palmitic & $17.34-19.2$ \\
& Stearic & 2.0 \\
Unsaturated fatty acid & Oleic & $73.3-78.73$ \\
& Linoleic & $2.4-3.93$ \\
& Linolenic & 2.2 \\
\hline
\end{tabular}

Many types of carotenoids were found, as listed in Table 2. As seen, the main contribution to the concentration of carotenoids comes from $\beta$-carotenes. The spectroscopic results presented later will be analyzed taking into account the contributions from $\alpha$-tocopherol (AT), $\beta$-carotene (BC), chlorophyll A (CA), oleic acid (OA) and palmitic acid (PA), which are the major components of Buriti oil. Since we are not taking into account all of its components, the discussion presented focus only on a qualitative analysis.
Table 2. Contents (ppm) of carotenoids present in the Buriti oil

\begin{tabular}{llll}
\hline Substance & $\begin{array}{l}\text { Amount } \\
(\mathrm{ppm})\end{array}$ & Substance & $\begin{array}{l}\text { Amount } \\
(\mathrm{ppm})\end{array}$ \\
\hline trans- $\beta$-carotene & $672 \pm 10$ & $\alpha$-carotene & $61 \pm 7$ \\
13-cis- $\beta$-carotene & $359 \pm 27$ & mutachrome & $45 \pm 1$ \\
9-cis- $\beta$-carotene & $150 \pm 18$ & - -carotene & $39 \pm 3$ \\
phytofluene & $150 \pm 8$ & $\beta$-zeacarotene & $38 \pm 1$ \\
zeaxantine & $98 \pm 4$ & $\gamma$-carotene & $13 \pm 1$ \\
$\beta$-10-apo-carotene & $70 \pm 3$ & $\delta$-carotene & $11 \pm 1$ \\
\hline
\end{tabular}

Fatty acids (palmitic and oleic) and $\alpha$-tocopherol were purchased from Merck \& Co. Inc. and Sigma-Aldrich Co., respectively. The oleic acid was used as received while the palmitic acid was diluted in a $2 \mathrm{~mol} \mathrm{~L}^{-1}$ ethanol solution.

\section{Absorption and emission spectra}

The absorption spectra were obtained in a Cary17 spectrophotometer with a resolution of $1.0 \mathrm{~nm}$. The fluorescence spectra were measured at right-angle with an optical fiber based USB 2000 Ocean Optics portable spectrometer integrating the overall signal. This enables us to desconsider any transient effect. All measurements were performed with the substances (in the liquid state) inside a $1 \mathrm{~cm}$ long quartz cuvette. As excitation source we used a tunable optical parametric amplifier (TOPAS, from Light Conversion) pumped by $150 \mathrm{fs}$ pulses at $775 \mathrm{~nm}$ delivered by a Ti: sapphire chirped pulse amplified system (CPA-2001, from Clark-MXR Inc.) operating at a $1 \mathrm{kHz}$ repetition rate. The FWHM pulse width delivered by the parametric amplifier was about $120 \mathrm{fs}$, and the beam transverse profile presented a nearly Gaussian distribution. All spectra were recorded at room temperature and the results shown below are the average of 10 runs.

\section{Results and Discussion}

Figure 1 shows part of the normalized absorption spectrum of Buriti oil and some of its constituents in the range $300-550 \mathrm{~nm}$. Absorption spectra of $\mathrm{BC}$ and $\mathrm{CA}$ were obtained from References 9 and 10, respectively. A high absorption for wavelengths shorter than $500 \mathrm{~nm}$ is observed. It should be noted that both $\mathrm{BC}$ and $\mathrm{CA}$ are responsible for the absorption from 500 down to $400 \mathrm{~nm}$, while AT, PA and OA give rise to the absorption for wavelengths shorter than $375 \mathrm{~nm}$. However, none of these compounds absorb significantly around $380 \mathrm{~nm}$, suggesting that the contribution of other compounds of Table 1, not studied here, should be considered to correctly reproduce the Buriti oil spectrum. 


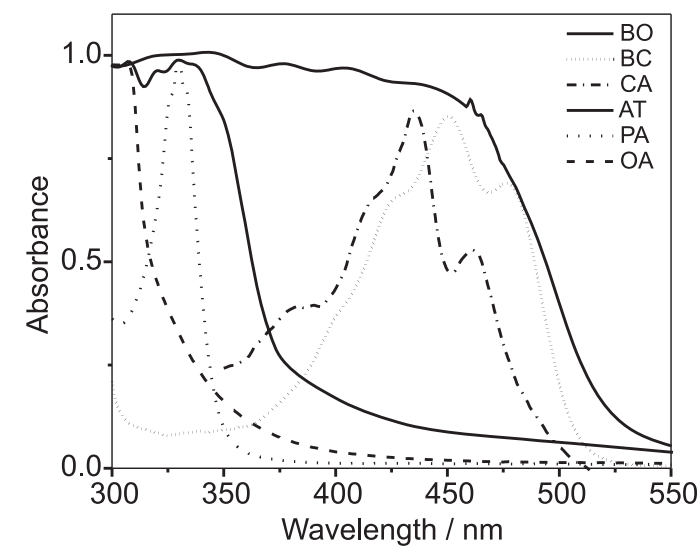

Figure 1 - Normalized absorbance spectra of Buriti oil and some of its components in the range $300-550 \mathrm{~nm}$. $\mathrm{BO}=$ Buriti oil, $\mathrm{BC}=$ $\beta$-carotene, $\mathrm{CA}=$ chlorophyll $\mathrm{A}, \mathrm{AT}=\alpha$-tocopherol, $\mathrm{PA}=$ palmitic acid and $\mathrm{OA}=$ oleic acid

Figure 2a presents the normalized absorption spectra of Buriti oil and some of its constituents in the range 550$800 \mathrm{~nm}$. The only absorption band observed at $665 \mathrm{~nm}$ should probably be attributed to CA (Q band).$^{10}$ Figure $2 \mathrm{~b}$ shows the normalized absorption spectra in the range 850$1100 \mathrm{~nm}$. It is observed that both AT and OA contribute to the band at $935 \mathrm{~nm}$, while that at $980 \mathrm{~nm}$ is much probably to AT. Figure $2 \mathrm{c}$ shows the normalized absorption spectra in the 1100-1500 $\mathrm{nm}$ interval where several bands are observed. It seems that the main contribution to the absorption profile comes mainly from the OA, although there exists some contribution from AT. Similar spectra were also observed for decanoic acid. ${ }^{11}$ Usually, in the near infrared (NIR) interval, OA shows strong bands at 1210, 1390,1410 , and $1430 \mathrm{~nm} \cdot{ }^{12}$ The band at $1210 \mathrm{~nm}$ is due to the second overtone of the $\mathrm{CH}_{2}$ stretching mode, and the remaining bands are assigned to combination modes of the $\mathrm{CH}$ fundamental stretching vibration with deformation vibrations of $\mathrm{CH}$ groups. ${ }^{12}$ According to the inset, the band at $1275 \mathrm{~nm}$ seems to be due to the AT. Figure $2 \mathrm{~d}$ shows two intense absorptions around 1730 and $1760 \mathrm{~nm}$ basically due to the OA, which is assigned to the first overtone of stretching vibrations for hydrogen-bonded $\mathrm{OH}$ and/or $\mathrm{CH}$ of both $\mathrm{CH}_{2}$ e $\mathrm{CH}_{3}$ groups.

There exist several papers already published reporting the emission spectra of many natural oils. ${ }^{13,14}$ However, none of them present the analysis based on the individual oil components. Figure 3 shows the emission spectra exhibited by Buriti oil and its components in the range $400-800 \mathrm{~nm}$ excited by $458 \mathrm{~nm}$ radiation. We observe three emission bands around 550, 670 and $760 \mathrm{~nm}$. For the band at $550 \mathrm{~nm}$ we have the contribution of $\mathrm{OA}, \mathrm{BC}$ and AT. According to reference 15, BC absorbing at $488 \mathrm{~nm}$ (and also $458 \mathrm{~nm}$ ) fluoresces in the range $530-920 \mathrm{~nm}$. The excitation wavelength drives the $1 \mathrm{~A}_{\mathrm{g}}^{-}(0) \rightarrow 1 \mathrm{~B}_{\mathrm{u}}^{+}(2)$
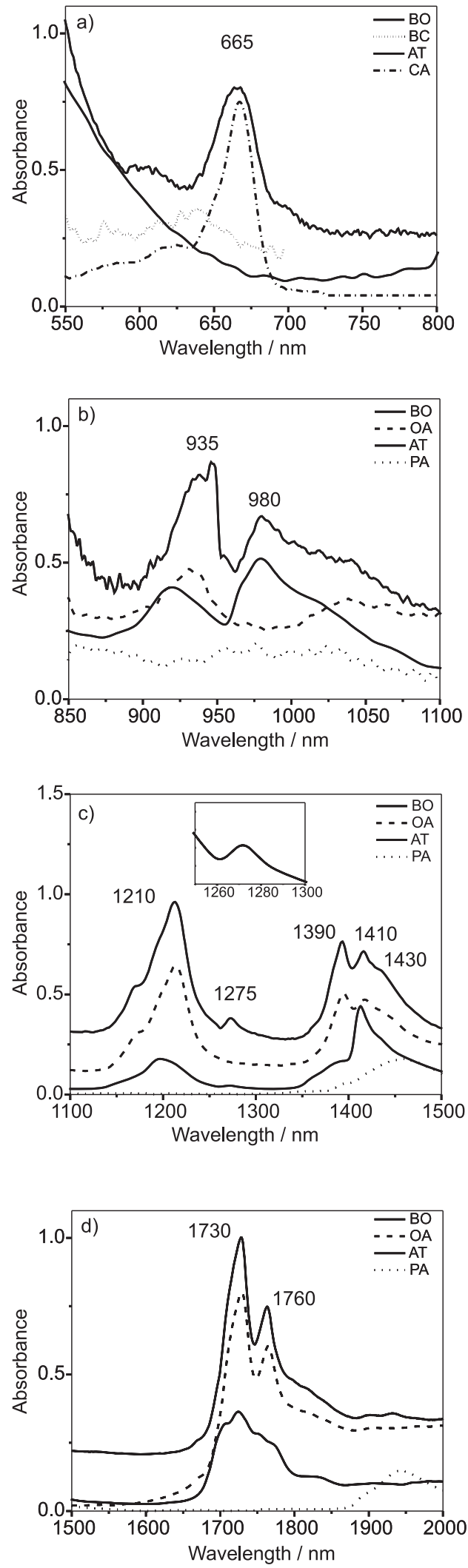

Figure 2 - Normalized absorbance spectra of Buriti oil and some of its components in different spectral ranges. (a) $550-800 \mathrm{~nm}$, (b) $850-1100 \mathrm{~nm}$, (c) $1100-1500 \mathrm{~nm}$ and (d) $1500-2000 \mathrm{~nm}$. The inset in Figure $2 \mathrm{c}$ is a close view of region from 1250 to 1300 of $\alpha$-tocopherol. 
absorptive transition producing a fluorescence spectrum due to the $1 \mathrm{~B}_{\mathrm{u}}^{+} \rightarrow 1 \mathrm{~A}_{\mathrm{g}}^{-}(0,1,2,3)$ emissive transitions in the range $500-600 \mathrm{~nm}$ while the very weak fluorescence spectrum observed for $\lambda>600 \mathrm{~nm}$ is mainly due to the $2 \mathrm{~A}_{\mathrm{g}}^{-} \rightarrow 1 \mathrm{~A}_{\mathrm{g}}^{-}(0,1,2,3,4)$ emissive transitions.

The remaining bands to be analyzed are much probably due to CA. According to Rebane and Avarmaa, ${ }^{16}$ a fluorescence emission at $670 \mathrm{~nm}$ has been observed in CA exciting it at $480-490 \mathrm{~nm}$ (B band). This fluorescence comes from the $S_{1} \rightarrow S_{0}$, emissive transition. The weak fluorescence band at $760 \mathrm{~nm}$ is not observed in isolated complexes, ${ }^{17}$ which presents a fluorescence band at 720 $735 \mathrm{~nm}$. It has been shown that cyanobacterial cells and membranes exhibit a fluorescence band at 750-760 nm, which is emitted by long wavelength chlorophyll absorbing at $735 \mathrm{~nm}$ (Q band). ${ }^{18}$ Hence, the long wavelength emitted by chlorophyll is re-absorbed by it (cf. Figure 2a) resulting in the fluorescence band at 760 $\mathrm{nm}$. According to Osbone and Fearn, ${ }^{19}$ this emission band is formed only in high molecular mass complexes, which is the case of complex multicomponent compounds like Buriti oil.

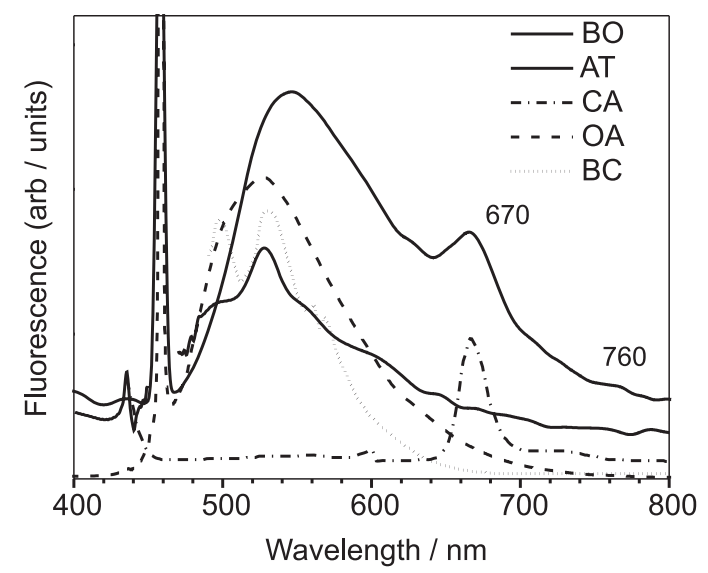

Figure 3 - Fluorescence spectra of Buriti oil and some of its components in the range $400-800 \mathrm{~nm}$.

In order to make sure the assignment of the fluorescence bands observed, we have varied the wavelength of the exciting laser from 458 to $514 \mathrm{~nm}$. In Figure 4 we plot the behavior of the ratio between the intensities of the bands at 550 and 670 (I550/I670) nm as a function of the excitation wavelength.

By increasing the wavelength we observe that the ratio starts decreasing, being equal to one for $\lambda=488 \mathrm{~nm}$ and therefore becoming less than one for $\lambda \geq 496 \mathrm{~nm}$. Such a behavior indicates that as the wavelength increases, smaller is the contribution of $\mathrm{BC}, \mathrm{AT}$ and $\mathrm{OA}$ absorption bands as already shown in Figure 1. It should also be mentioned that the ratio increases a bit when $\lambda$ changes from 514 to

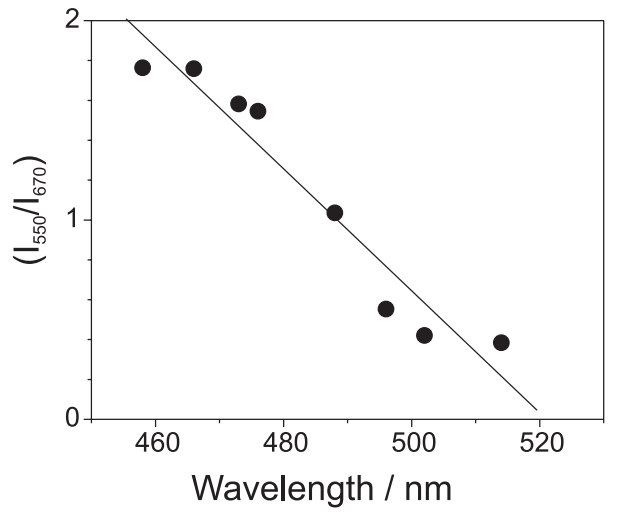

Figure 4 - Plot of the intensity ratio I550/I670 as a function of the excitation wavelength. The line is a guide for eyes.

$532 \mathrm{~nm}$. For this wavelength, the excitation is in between bands B and Q of CA, where the absorption is lower and therefore the intensity of the fluorescence band at $670 \mathrm{~nm}$ decreases with respect to the background signal. Only for wavelengths $\lambda>620 \mathrm{~nm}$ (the beginning of the $\mathrm{Q}$ band) this band becomes well defined and more intense with respect to the background.

\section{Conclusions}

Summarizing, we have presented a qualitative study of the absorption and emission spectra of Buriti oil and its major components at room temperature. Several absorption bands were observed in the range 300-2000 nm. They were tentatively identified and it was observed that for shorter wavelengths $(\lambda<500 \mathrm{~nm})$ the absorption is mainly to some of its components as OA, PA, AT, BC and CA. For longer wavelengths $(\lambda>1000 \mathrm{~nm})$ it seems that the main contributor is the OA. The emission spectrum of Buriti oil presents three bands in the range 400-800 $\mathrm{nm}$ which were also assigned. Many of its individual components contribute to the shorter wavelength band at around $570 \mathrm{~nm}$, while basically only CA contributes to the 670 and $760 \mathrm{~nm}$ bands.

\section{Acknowledgments}

This work was supported by the CNPq under contract №. 475191/01-3, FUNCAP under contract No. 219/01, FUNTEC under contract No. 015/00, and FAPESP under contract $\mathrm{N}^{\circ}$. 01/07410-2.

\section{References}

1. Garcia-Quiroz, A.; Moreira, S.G.C.; De Morais, A.V.; Silva, A.S.; Da Rocha, G.N.; Alcantara Jr., P.; Instrum. Sci. Technol. 2003, 31, 93 . 
2. Tappin, M.R.R.; Pereira, J.F.G.; Lima, L.A.; Siani, A.C.; Mazzei J.L.; Ramos, M.F.S.; Quim. Nova 2004, 27, 236.

3. da Veiga V. F.; Pinto A. C.; Quim. Nova 2002, 25, 273.

4. Sarubbo, L.A; Marcal, M.C.R.; Campos-Takaki, G.M.; Arq. Biol. Tecnol. 1997, 40, 707.

5. Yang, C.-W.; Peng, C.-L.; Duan, J.; Chen, Y.-Z.; Bot. Bull. Acad. Sin. 2002, 43, 181.

6. Bernal-Alvarado, J.; Mansanares, A.M.; Da Silva, E.C.; Moreira, S.G.C.; Rev. Sci. Instrum. 2003, 74, 697.

7. Albuquerque, M.L.S.; Guedes, I.; Alcantara Jr., P.; Moreira, S.G.C.; Vib. Spectrosc. 2003, 33, 127.

8. Da Rocha, G.N.; Brodzki, D.; Djegamariadassou, G.; Fuel 1993, 72, 543.

9. http://www.chm.bris.ac.uk, accessed in May 2004.

10. Barbosa Neto, N.M.; Corrêa, D.S.; dos Santos Jr., D.S.; Misoguti, L.; Oliveira Jr., O.N.; Zílio, S.C.; Mendonça, C.R.; Mod. Phys. Lett. B 2003, 17, 83.

11. Iwahashi, M.; Hachiya, N.; Hayashi, Y.; Matsuzawa, H.; Suzuki, M.; Fujimoto, Y.; Ozaki, Y.; J. Phys. Chem. 1993, 97, 3129.

12. Sasic, S.; Muszynski, A.; Ozaki, Y.; J. Phys. Chem. A 2000, 104,6380 .
13. Zandomeneghi, M.; Carbonaro, L.; Caffarata, C.; J. Agric. Food Chem. 2005, 53, 759.

14. Sikorska, E.; Gorecki, T.; Khmelinskii, I.V.; Henrance, R.; Bourdelance, J.L.; Sikorski, M.; Koziol, J.; Food Chem. 2005, 89, 217.

15. Onaka, K.; Fujii, R.; Nagae, H.; Kuki, M.; Koyama, Y.; Watanabe, Y.; Chem. Phys. Lett. 1999, 315, 75.

16. Rebane, K.K.; Avarmaa, R.A.; Chem. Phys. 1982, 68, 191.

17. Shubin, V.V.; Bezsmertnaya, I.N.; Karapetyan, N.V.; FEBS Lett. 1992, 309, 340.

18. Shubin, V.V.; Murthy, S.D.S.; Karapetyan, N.V.; Mohanty, P.; Biochim. Biophys. Acta 1991, 1060, 28.

19. Osbone, B.G.; Fearn, T. In Near Infrared Spectroscopy in Food Analysis; Lonman Scientific \& Technical: New York, 1986, p. 28.

Received: November 4, 2004 Published on the web: August 30, 2005

FAPESP helped in meeting the publication costs of this article. 